\title{
TiC Coating on Titanium by Carbonization Reaction Using Spark Plasma Sintering*1
}

\author{
Tomohiro Hayashi ${ }^{1, * 2}$, Kiyotaka Matsuura ${ }^{2}$ and Munekazu Ohno ${ }^{2}$ \\ ${ }^{1}$ Graduate School of Engineering, Hokkaido University, Sapporo 060-8628, Japan \\ ${ }^{2}$ Faculty of Engineering, Hokkaido University, Sapporo 060-8628, Japan
}

\begin{abstract}
Hard TiC coating layer is formed on commercially pure titanium by heat treatment in a spark plasma sintering (SPS) mold filled with graphite powder. In case of heat treatment at $1243 \mathrm{~K}$ for $3600 \mathrm{~s}$, the obtained thickness of the coating layer is about $10 \mu \mathrm{m}$ and almost uniform. This coating itself consists of TiC and graphite, and there is no titanium oxide detected by X-ray diffractometer (XRD). Vickers hardness tests have revealed that the hardness of titanium coating is $1600 \mathrm{HV}$, which is much higher than that of the titanium substrate (130 HV). The hard TiC coating on titanium is considered to be advantageous when applied to load bearing parts of hard tissue replacements. The growth behavior of TiC is parabolic with an activation energy of $218.6 \mathrm{~kJ} / \mathrm{mol}$. This value is close to the activation energy of carbon diffusion in TiC. Therefore, the growth rate of $\mathrm{TiC}$ is rate-controlled by inward diffusion of carbon in the TiC phase. [doi:10.2320/matertrans.L-M2013829]
\end{abstract}

(Received May 14, 2013; Accepted August 7, 2013; Published October 11, 2013)

Keywords: titanium, TiC, surface modification, spark plasma sintering

\section{Introduction}

Titanium and its alloys are characterized by a high specific strength as well as a good biological compatibility. For this reason they are used as biomaterials and they can be applied in many ways such as dental implants. ${ }^{1,2)}$ Biomaterials often react with the human body and the reaction products are harmful in some situations. ${ }^{3)}$ Titanium, however, has generally a low reactivity with the human body combined with a high ability to attach to tissues. One of the weak points of titanium is its poor wear resistance. Titanium implants produce abrasion powder as a result of friction in the human body. According to Hossain et al., this powder is harmful to our health. ${ }^{4,5)}$ Therefore, an increase in hardness and wear resistance of titanium is needed.

Many hard ceramic coatings on various metal substrates have been studied in order to improve wear resistance. ${ }^{6-9)}$ In the case of titanium, titanium carbide (TiC) coatings produced by physical vapor deposition (PVD) and chemical vapor deposition (CVD) have been studied.9,10) $\mathrm{TiC}$ has a high hardness, a good biological compatibility and a good ability to attach to the bone and tissue. ${ }^{11)}$ Thus the forming of a TiC coating on titanium by PVD or CVD is a useful method for improving the wear resistance of titanium-based biomaterials. However, the adherence of the coating on the substrate is not good enough to completely prevent peeling of the coating. ${ }^{12,13)}$ In addition, it is reported that the adherence of the PVD produced coating deteriorates during the immersion in a simulated body fluid. ${ }^{14)}$

By contrast, carburizing is a well-known method for surface hardening treatment of steel showing a good bondability. ${ }^{15)}$ In this method hydrocarbon gases such as methane and propane are used. However, gas carburizing takes a long-time and requires high-temperature treatments, which leads to negative effects such as grain coarsening of

\footnotetext{
${ }^{* 1}$ This Paper was Originally Published in Japanese in J. JILM 62 (2012) 233-236.

${ }^{* 2}$ Graduate Student, Hokkaido University. Present address: UACJ Corporation, Fukaya 366-8511, Japan
}

the titanium substrate. In this study, the authors have applied spark plasma sintering (SPS) method to the gas carburizing treatment in order to reduce the carburization time and temperature. SPS method is a sintering method based on high energy due to plasma which enables short-time and lowtemperature sintering of the powder. This study aims to carburize commercially pure titanium by SPS method and to form a hard carbide coating.

\section{Experimental Procedures}

A commercially pure titanium plate with a thickness of $1 \mathrm{~mm}$ was used as the substrate material. The purity of the titanium was $99.5 \%$. Small samples with a width of $7 \mathrm{~mm}$ and a length of $13 \mathrm{~mm}$ were cut from this plate. The samples were polished by using emery paper (\#400) and cleaned with ethanol at room temperature for $1200 \mathrm{~s}$ using an ultrasonic bath. As a carbon source, graphite powder was used. The purity of the powder was $99.0 \%$ and the diameter was about $1 \mu \mathrm{m}$.

First of all a graphite die of 40 and $20 \mathrm{~mm}$ outer and inner diameter and $40 \mathrm{~mm}$ in height was filled with $7 \mathrm{~g}$ of the graphite powder. The die's bottom was plugged up by a graphite punch. Then the titanium plate sample was embedded in the powder. In the following step another graphite punch was plugged in the upper hole of the die. After that the die with the punches was set in an SPS machine, as illustrated in Fig. 1. Then, the powder was pressed unidirectionally at $10.5 \mathrm{MPa}$ in a vacuum chamber at a pressure of $10 \mathrm{~Pa}$, and the die was heated at a rate of $0.83 \mathrm{~K} / \mathrm{s}$ to a given temperature and held for a given period of time. After holding, the electric power of the SPS machine was switched off, and the graphite mold was naturally cooled inside the vacuum chamber. The holding temperature was set to 1043,1143 and $1243 \mathrm{~K}$ and the holding time was set to 0 , $300,600,1200,1800$ and $3600 \mathrm{~s}$.

The temperature was monitored on the surface of the graphite die using a radiation thermometer. The sample temperature was evaluated from the surface temperature using a calibration curve obtained in a preliminary experiment. 


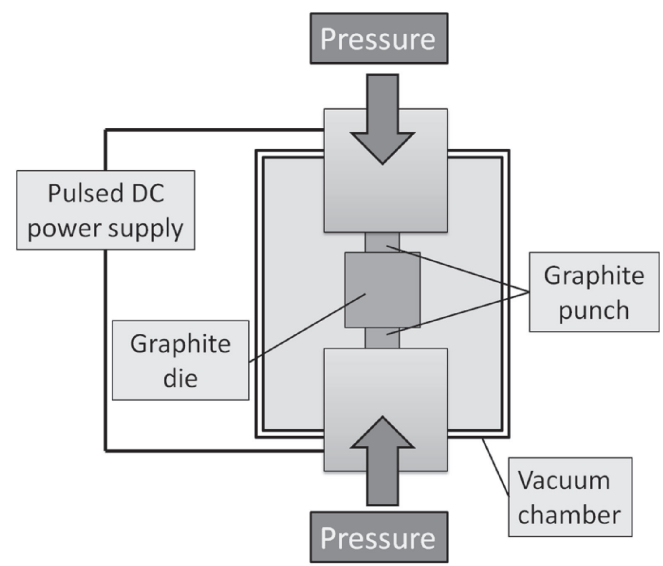

Fig. 1 Schematic illustration of the SPS equipment.

Pure copper and silver were used as the temperature calibration materials. The temperature described in this paper corresponds to the calibrated one.

After cooling, the samples were sectioned and polished to observe the surface of the cross section using an optical microscope and a scanning electron microscope (SEM). Some of the samples were etched for metallographical investigation using an aqueous solution that consisted of $5 \mathrm{~mL}$ of hydrogen peroxide, $2 \mathrm{~mL}$ of hydrogen fluoride and $100 \mathrm{~mL}$ of distilled water. The thickness of the coating layer was measured using graphic software called Canvas 11 .

The chemical composition of the cross section of the samples was analyzed using an electron probe micro analyzer (EPMA) at an accelerating voltage of $15 \mathrm{kV}$ and a probe current of $30 \mathrm{nA}$.

The crystalline structure was determined on the surface of the samples using an X-ray diffractometer (XRD) with $\mathrm{CuK}_{\alpha}$ (tube voltage of $40 \mathrm{kV}$ and current of $40 \mathrm{~mA}$ ).

The hardness of the samples' surface was evaluated using the Vickers hardness test with an applied load of $25 \mathrm{~g}$ and a holding time of $15 \mathrm{~s}$. The hardness was measured at 16 different points on the surface and averaged for each sample.

\section{Results and Discussions}

\subsection{Analysis of the coating layer}

Figure 2 shows a backscattered electron (BSE) image of the cross section of the sample treated at $1243 \mathrm{~K}$ for $1800 \mathrm{~s}$ by the SPS method. The upper dark part is the resin used for the sample mounting, and the lower bright part is the titanium substrate. The gray part in between is the coating layer which has a thickness of approximately $8 \mu \mathrm{m}$. There is no crack at the coating/substrate interface and no peeling of the coating layer occurs. This indicates a good adherence of the coating on the substrate. Figure 3 illustrates the concentration profiles of $\mathrm{Ti}, \mathrm{C}$ and $\mathrm{O}$ obtained by EMPA analysis on a line crossing the interface between the coating and the substrate. Because the coating layer has an approximated composition of $\mathrm{Ti}: \mathrm{C}=6: 4$, it is considered from a Ti-C binary equilibrium phase diagram ${ }^{16)}$ that the coating layer is composed of TiC. Oxygen was detected in the EPMA analysis. The oxygen concentration was slightly high in the titanium substrate, which is considered to be

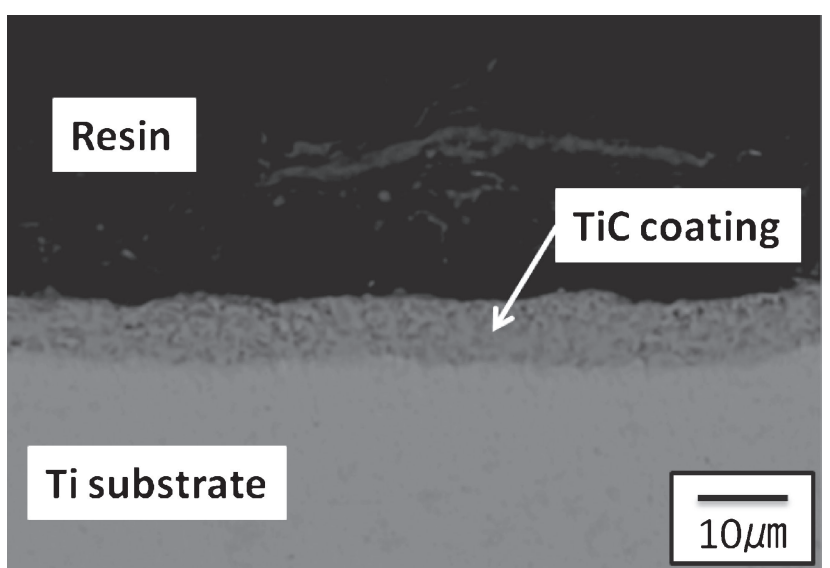

Fig. 2 BSE image of the cross section of the sample treated at $1243 \mathrm{~K}$ for $1800 \mathrm{~s}$ by the SPS method.

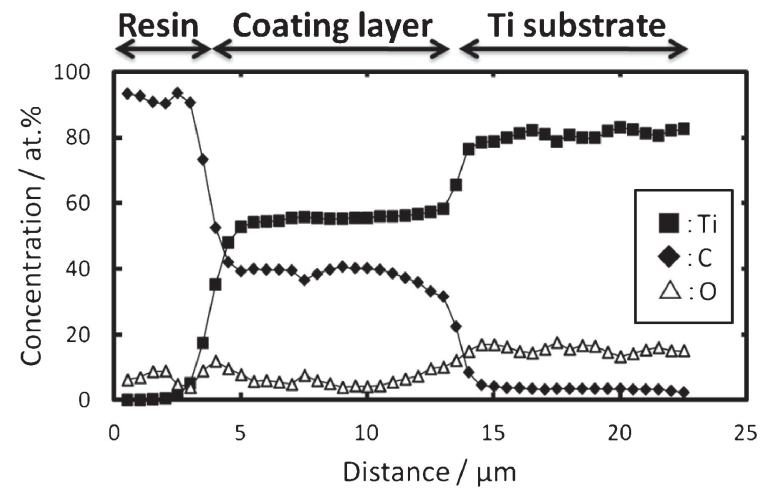

Fig. 3 EPMA profiles on the cross section of the sample treated at $1243 \mathrm{~K}$ for $1800 \mathrm{~s}$ by the SPS method.

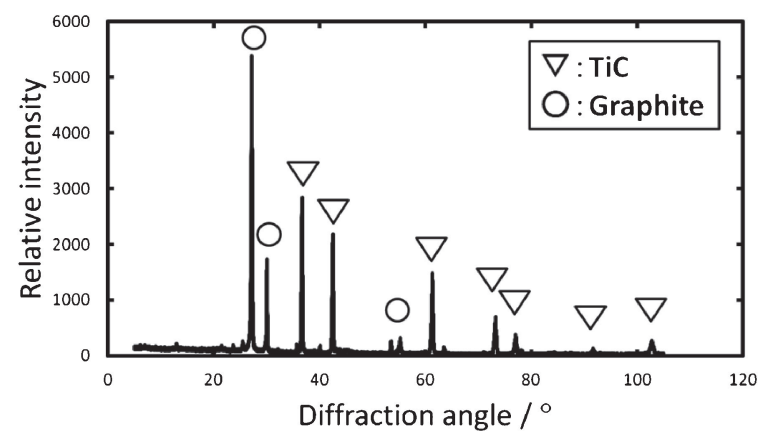

Fig. 4 XRD spectrum for the coating surface of the sample treated at $1243 \mathrm{~K}$ for $1800 \mathrm{~s}$ by the SPS method.

caused by the oxide film formed during the polishing process. The presence of the TiC coating on the surface of the substrate was confirmed by the XRD analysis, as highlighted in Fig. 4. Figure 4 also shows the presence of graphite on the sample's surface, which is considered to be the residual graphite powder after cleaning the surface.

In general, titanium is easily oxidized at high temperatures, because of its high reactivity with oxygen. However, the XRD analysis did not detect any titanium oxide peaks in Fig. 4. This may be because the SPS process was performed in vacuum or because the plasma spark of extremely high temperatures at the titanium surface avoided the formation 

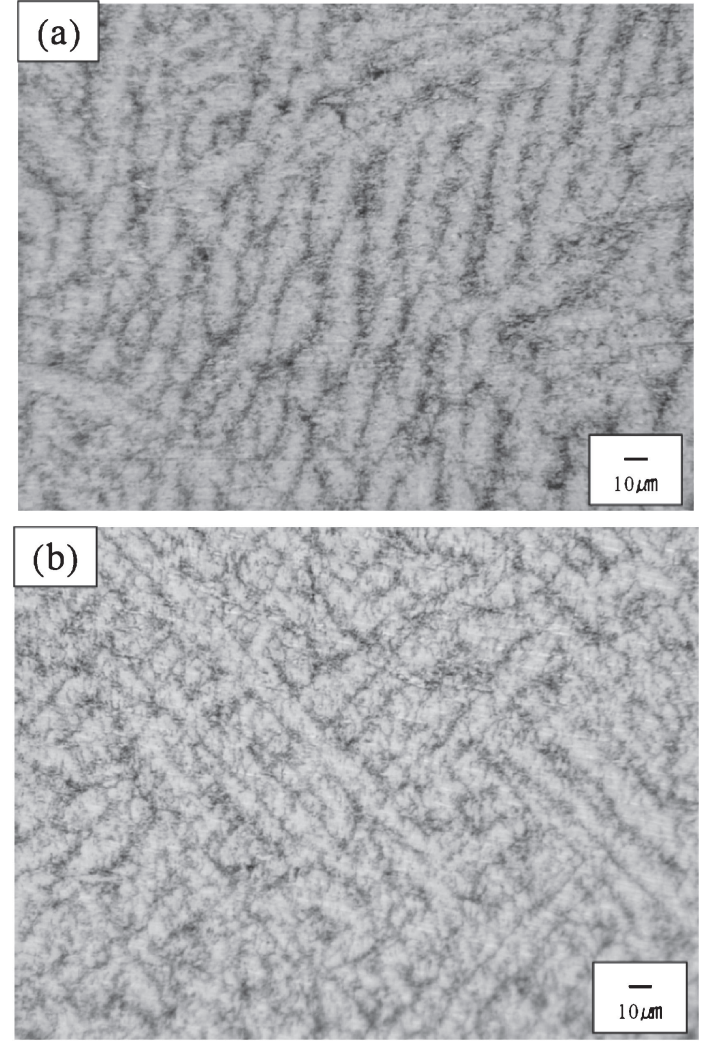

Fig. 5 Microstructures of the titanium substrate treated at $1243 \mathrm{~K}$ by the SPS method for (a) $0 \mathrm{~s}$, (b) $3600 \mathrm{~s}$.

of oxides on the surface. According to Voudouris and Angelopoulos, oxygen existing in TiC phase inhibits carbon diffusion. ${ }^{17)}$ The absence of the oxide is advantageous for the growth of the $\mathrm{TiC}$ coating layer.

\subsection{Properties of the $\mathrm{TiC}$ coating}

Figure 5 shows microstructures of the titanium substrate of samples treated at $1243 \mathrm{~K}$ by the SPS method for $0 \mathrm{~s}$ (Fig. 5(a)) and 3600 s (Fig. 5(b)). Comparison between these microstructures indicates that there is very little grain growth during the heat treatment, which implies that this coating method does not lead to deterioration in mechanical properties of the substrate originating from grain coarsening.

Figure 6 shows the Vickers hardness of the surfaces with and without $\mathrm{TiC}$ coating. The TiC-coated sample exhibits an excellent hardness of $1600 \mathrm{HV}$, which is much higher than the hardness of the sample without coating $(130 \mathrm{HV})$. Increase in hardness of titanium-based biomaterials brings about an advantage in the applications to load bearing parts of hard tissue replacements. However, the Vickers hardness of this TiC coating is lower than that of bulk TiC $(3200 \mathrm{HV}) .{ }^{18)}$ This difference may originate from the thinness of the coating $(10 \mu \mathrm{m})$. The surface hardness is generally underestimated due to plastic deformation of the substrate when the hard surface layer is very thin compared to the soft substrate. The surface roughness of the coating could be another reason as well. Figure 7 shows the micrograph of the coating surface after slight polishing. The surface is rough even after polishing, which can be explained by dropping of the residual graphite powder from the surface during polishing. It is possible that the roughness of the surface caused the

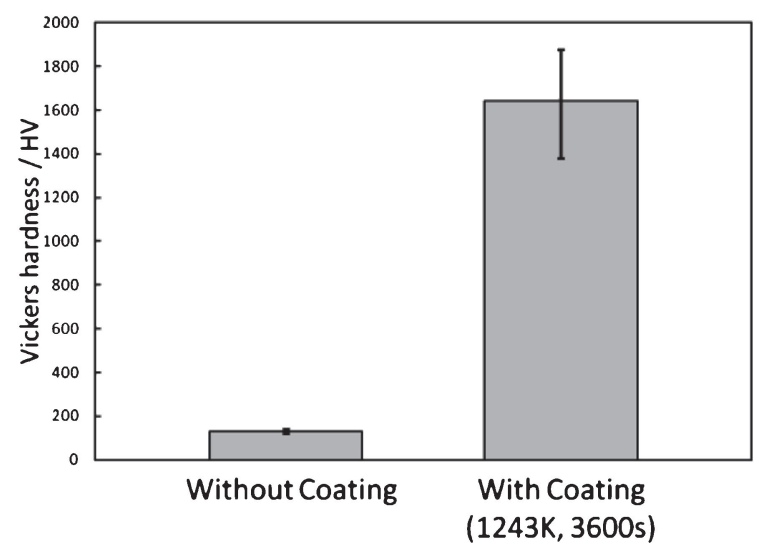

Fig. 6 Vickers hardness of the surfaces with and without TiC coating.

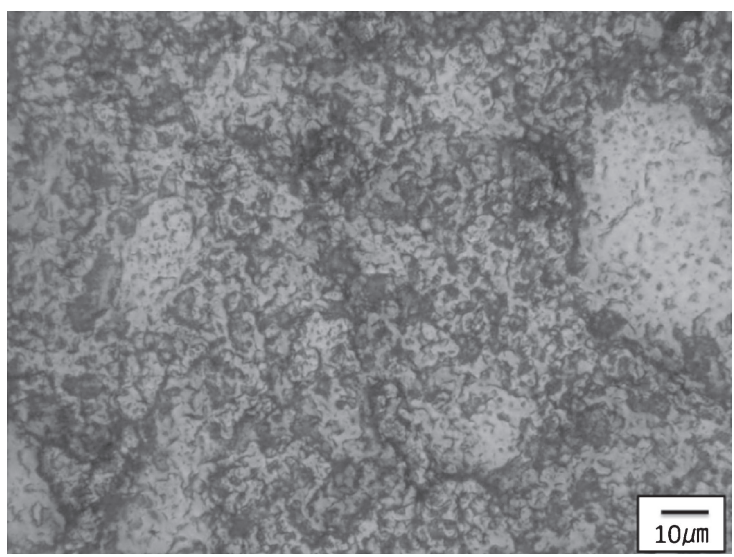

Fig. 7 Micrograph showing the coating surface of the sample treated at $1243 \mathrm{~K}$ for $3600 \mathrm{~s}$ by the SPS method.

reduction in surface hardness from the bulk TiC hardness. However, a rough surface can also be regarded as an advantage. Roughness can cause an excellent ability to attach to the bone and cell as it was shown for titanium implants. ${ }^{14,19-21)}$

\subsection{Growth kinetics of the coating}

Figure 8 shows the relationship between square of thickness of the TiC coating layer and holding time. The thickness increases with the increases of the holding temperature and time. Moreover, the square of the thickness is proportional to the holding time. That means that the growth of the coating is rate-controlled by diffusion, obeying the parabolic law described by eq. (1). ${ }^{22)}$

$$
x^{2}=k \cdot t
$$

where $x$ is the thickness of the coating, $k$ is the parabolic rate constant and $t$ is the holding time. The parabolic rate constant depends on the temperature, and it is generally described by eq. (2). ${ }^{22)}$

$$
k=k_{0} \cdot \exp (-Q / R T)
$$

where $k_{0}$ is a constant, $Q$ is the activation energy and $R$ is the gas constant $(=8.314 \mathrm{~J} /(\mathrm{mol} \cdot \mathrm{K}))$. Figure 9 shows the Arrhenius plots for the parabolic rate constant of the coating growth. From this figure, the activation energy of coating growth was calculated to be about $218.6 \mathrm{~kJ} / \mathrm{mol}$. According 


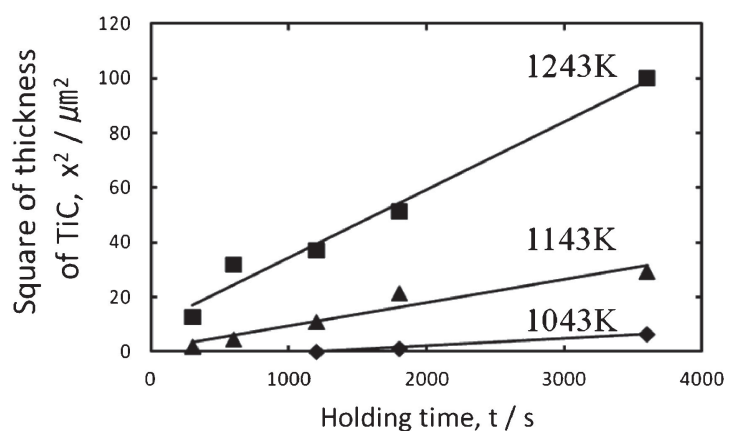

Fig. 8 Relationship between square of thickness of TiC coating layer and holding time.

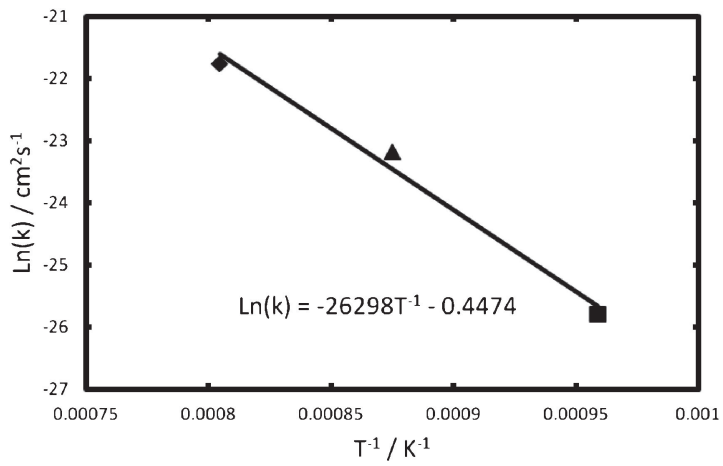

Fig. 9 Arrhenius plots for parabolic rate constant of TiC growth.

to Khina et al., the activation energy of carbon diffusion in $\mathrm{TiC}$ is about $240-460 \mathrm{~kJ} / \mathrm{mol}$ and that of titanium diffusion in $\mathrm{TiC}$ is about $740 \mathrm{~kJ} / \mathrm{mol}^{23)}$ The activation energy in this study is close to that of carbon diffusion in $\mathrm{TiC}$, which indicates that $\mathrm{TiC}$ growth is controlled by inward diffusion of carbon in $\mathrm{TiC}$ phase.

\section{Conclusions}

In this study, the authors developed an SPS carbonization method of titanium surface. The results can be summarized as follows.

(1) $\mathrm{TiC}$ coating layer can be fabricated on commercially pure titanium substrate using the SPS method.
(2) The Vickers hardness of the titanium has quite improved by forming the $\mathrm{TiC}$ coating. Therefore, it is expected that the TiC-coated titanium can be utilized as biomaterials having a good wear resistance.

(3) The TiC coating grows by obeying the parabolic law, and the activation energy of $\mathrm{TiC}$ growth is about $218.6 \mathrm{~kJ} / \mathrm{mol}$. This value is close to the activation energy of carbon diffusion in $\mathrm{TiC}$, which indicates that the growth of $\mathrm{TiC}$ is rate-controlled by inward diffusion of carbon in $\mathrm{TiC}$ phase.

\section{REFFERNCES}

1) Y. Okazaki: J. JILM 49 (1999) 613-620.

2) A. Kamiya and T. Nonami: J. JILM 51 (2001) 195-201.

3) Y. Ikada: Seitai-Zairyogaku, (Sangyo Tosho Publishing, Japan, 1994) pp. 51-61.

4) A. Hossain, S. Okawa and O. Miyakawa: Dent. Mater. 22 (2006) 346352.

5) T. Hanawa: J. JILM 55 (2005) 553-556.

6) M. Takaya: J. Surf. Finish. Soc. Japan 41 (1990) 1074-1080.

7) Y. Harada: Turbomachin. 23 (1995) 93-99.

8) A. Suda and K. Mori: J. Surf. Finish. Soc. Japan 57 (2006) 137-140.

9) M. Oishi: J. Surf. Finish. Soc. Japan 41 (1990) 1125-1132.

10) M. Kawada: J. Japan Soc. Precision Eng. 46 (1980) 946-952.

11) M. Brama et al.: Biomaterials 28 (2007) 595-608.

12) S. Kameoka, S. Motonishi and H. Uchida: Surf. Coat. Technol. 169170 (2003) 316-320.

13) X. Yin, I. Gotman, L. Klinger and E. Y. Gutmanas: Mater. Sci. Eng. A 396 (2005) 107-114

14) T. Narushima: J. JILM 58 (2008) 577-582.

15) The Japan Institute of Metals and Materials: Tekko-Zairyo, (1985) pp. $117-122$.

16) D. A. Andersson, P. A. Korzhavyi and B. Johansson: Comput. Coupl. Phase Diagrams Thermochem. 32 (2008) 543-565.

17) N. Voudouris and G. N. Angelopoulos: Surf. Coat. Technol. 115 (1999) $38-44$.

18) The Ceramics Society of Japan: Ceramics Engineering Hand Book, (2002) pp. 123-124.

19) Y. Kameyama, J. Komotori and T. Yamada: J. Japan Soc. Abrasive Technol. 49 (2005) 86-89.

20) H. Itahashi, T. Miyazaki, S. Fujimori and W. S. Lee: J. Japan Soc. Dent. Mater. Devices 14 (1995) 136-141.

21) K. Suzuki, K. Aoki and K. Ohya: Bone 21 (1997) 507-514.

22) H. Sudo, I. Tamura and T. Nishizawa: Kinzokusosikigaku, (Maruzen, 1972) p. 66.

23) B. B. Khina, B. Formanek and I. Solpan: Physica B 355 (2005) 14-31. 